\title{
E-LEARNING-BASED COMPETENCE DEVELOPMENT IN LOGISTICS
}

\author{
Gaby Neumann, Michael Müller, Rudi Köhler
}

\section{Abstract}

The logistics field of knowledge and professional competence is highly multidisciplinary and complex but also continuously and very dynamically developing. This does not only require constant updating of educational programmes but also systematic training of logistics professionals in order to avoid or reduce professional competence gaps. Workplace learning amongst others in combination with e-learning methodology seems to be an appropriate way to support professional competence development in logistics, too. The paper presents some research aspects particularly related to logistics competence profiling and development and derives conclusions on nowadays competence requirements with logistics professionals. This forms the basis for introducing a framework to help in specifying a person's level of logistics competence, recommending suitable learning units and supporting individual competence development as it results from the EU-funded lot4eng.com project. E-learning design to populate the lot4eng.com portal is discussed before lessons learned and conclusions on further work are derived. With this the paper wants to contribute to ongoing research on how to foster lifelong learning.

\section{Zusammenfassung}

Die Logistik ist ein hochgradig interdisziplinäres, komplexes Wissensgebiet und Kompetenzfeld, das sich kontinuierlich und sehr dynamisch weiterentwickelt. Dies erfordert nicht nur eine fortgesetzte Anpassung von Ausbildungsangeboten, sondern auch die systematische Weiterbildung von Logistikern, um Defizite in der beruflichen Handlungskompetenz zu vermeiden oder abzubauen. Lernen am Arbeitsplatz, eventuell in Verbindung mit E-Learning, erscheint als geeigneter Weg, die Entwicklung von beruflicher Handlungskompetenz auch in der Logistik zu unterstützen. Der Beitrag stellt verschiedene Ansätze für die Kompetenzermittlung und -entwicklung speziell in der Logistik dar und leitet Schlussfolgerungen zu den heutigen Kompetenzanforderungen bei Logistikpraktikern ab. Dies bildet die Basis für einen Handlungsrahmen, der im EU-geförderten Projekt lot4eng.com entstanden ist und hilft, das logistische Kompetenzniveau einer Person zu spezifizieren, geeignete Lerneinheiten zu seiner Steigerung vorzuschlagen und die individuelle Kompetenzentwicklung zu unterstützen. Im Weiteren wird die Gestaltung von E-Learning zum Füllen der lot4eng.com-Plattform diskutiert, bevor Erfahrungen aus der Projektarbeit und Schlussfolgerungen für die weitere Arbeit abgeleitet werden. Damit möchte der Beitrag die laufende Forschung dazu, wie lebenslanges Lernen unterstützt werden kann, anreichern.

\section{INTRODUCTION}

The need for education and training in logistics is widely accepted with individuals, companies and the academic world. To be in line with the ongoing rapid development of the logistics field of knowledge and practical application, professional knowledge and skills need to be updated continuously by all those who

work in the field of logistics, or

- work in other fields but need to take logistics aspects into consideration, or

- want to or need to understand the logistics context from the technological, economic, environmental, administrative or social point of view.
Even initial logistics education processes at vocational and higher education levels must be part of these dynamic changes to enable their graduates to meet employers' needs and perform well in a highly competitive and rapidly changing market.

New forms of logistics education and training processes and new scenarios they are settled in are required to let logistics learning be as flexible as needed with respect to:

(i) learners (in the widest sense), particularly in respect of their individual targets, motivations to learn, specific requirements and constraints,

(ii) varying learning needs resulting from the learner's targets, moti- vations, requirements and constraints, e.g. scope and level of knowledge, particular skills, and

(iii) appropriate learning resources developed and used in the form of units, modules and courses fulfilling learning needs and helping learners to reach their required, established goals.

Due to the complexity and multidisciplinarity of the logistics field of knowledge and competence and because of the strong need for being capable of dealing with challenges deriving from changing situations which are always new or slightly different to prior experience at least, education and training in logistics must enable the learner 
- to bridge the traditional gap between engineering and business administration aspects of logistics,

- to efficiently get self-familiar with permanently arising new topics,

- to professionally act in a wide variety of knowledge areas, and

- to discuss with or even mediate between experts from different knowledge domains.

In fact, technology cannot meet all of these challenges, but a proper design of the learning environment by combining up-to-date technology with modern pedagogy can provide distinctive support. Rapidly developing information and communication technology, for example, has provided an ever-increasing variety of those e-learning scenarios. However, to let those virtual learning environments really enable high-quality learning processes in logistics, too, a fundamental change of pedagogic paradigms and a wide-span cultural shift are required at all levels of education and training. With this it is necessary to understand (and accept) that out more is expected of (logistics) learners and teachers operating virtually than within a traditional (classroom or) distance regime and this does not always suit all participants (Ryan and Woodward 1998). So, it is extremely important to introduce learners (and teachers) to this new way (culture) of learning and teaching, including how to learn (and teach) within a virtual environment. For this, there is a general need to help learners understand their targets and constraints, to translate them into educational requirements and to configure personalized learning paths composed of available resources. This is the clue to achieve the required and intended improvement of knowledge, abilities and skills, to reach the individual targets of the learning process in shorter time and better quality - no matter if we talk about formal education scenarios (e.g. at universities) or informal learning and self-learning experiences (e.g. by professionals). The latter exactly represents the area of activity a European project supported by the European Commission's
Lifelong Learning Programme was settled down in.

The lot4eng.com (Logistics Open Training for Engineering Competence) project brought together partners from Poland, Italy and Germany who already collaborated in different previous projects which all aimed at supporting logistics professionals in improving their knowledge by use of multimedia and e-learning materials and web-based platforms. lot4eng. com has been inspired by the shortage of logistics engineers, which has already been and is yet to be faced by many countries across Europe. Therefore, the objective of the project is to enhance engineering and managerial skills of employees at risk of developing a competence gap in the field of logistics (i.e. employees of logistics, manufacturing or distribution enterprises, and coaches, trainers or vocational trainers in logistics). This is to be achieved by providing easy real-time access to high quality e-learning materials directly in the workplace (e.g. via an internet portal), almost immediate personalized support in real-life problem-solving (e.g. through a questionbased access to specific multimedia instructions), and clear understanding of personal competence deficits and training needs (e.g. based upon individual competence gap analysis).

The paper presents some research background on professional competence development in logistics (Section 2), analyses empirically gathered competence requirements in logistics practice (Section 3), presents the lot4eng.com framework and platform for personalized logistics competence development (Section 4) and illustrates respective e-learning design (Section 5). Section 6 provides a summary and derives conclusions on lessons learned and future work.

\section{BACKGROUND AND RELATED WORKS}

Competence as a term is being used in many different ways and contexts. The most important aspect here is the clear separation of what is understood by 'competence' from the other quite frequently used terms 'knowledge' and 'qualification'. In the context of this paper 'competence' goes far beyond 'knowledge' and 'qualification'. According to the European Commission (2007) "competences are defined ... as a combination of knowledge, skills and attitudes appropriate to the context. Key competences are those which all individuals need for personal fulfilment and development, active citizenship, social inclusion and employment". From this it becomes clear that knowledge forms just a basis for competence, whereas qualification typically refers to the outcome of a particular formal training situation. This differentiation is particularly relevant when discussing about how to measure and assess an individual's competence. The assessment of knowledge or qualification is typically subject to formalized, standardized assessment scenarios and examination. In contrast to this (professional) competence becomes visible not until the ability to individually, creatively deal with more or less complex (daily or professional) situations was demonstrated and related problems were solved purposefully and successfully (Neumann et al. 2005).

In the end, individual logistics competence is based upon a person's knowledge, experience and ability to act in a self-organised and creative way. It is nothing to be achieved once and then remain forever, but it has to be subject to an ongoing individual development process in order to continuously improve knowledge, abilities and skills and raise the own level of competence.

A generic framework for systematic competence development in logistics was proposed by Neumann et al. (2005). This model consists of four core elements (see Figure 1):

- Situation analysis with respect to both the existing individual logistics competence and a target competence level fitting to the personal work and life environment, but also meeting competence requirements derived from company objectives.

- Needs analysis and specification in view of the necessary competence development in order to achieve personal targets and company objectives. 


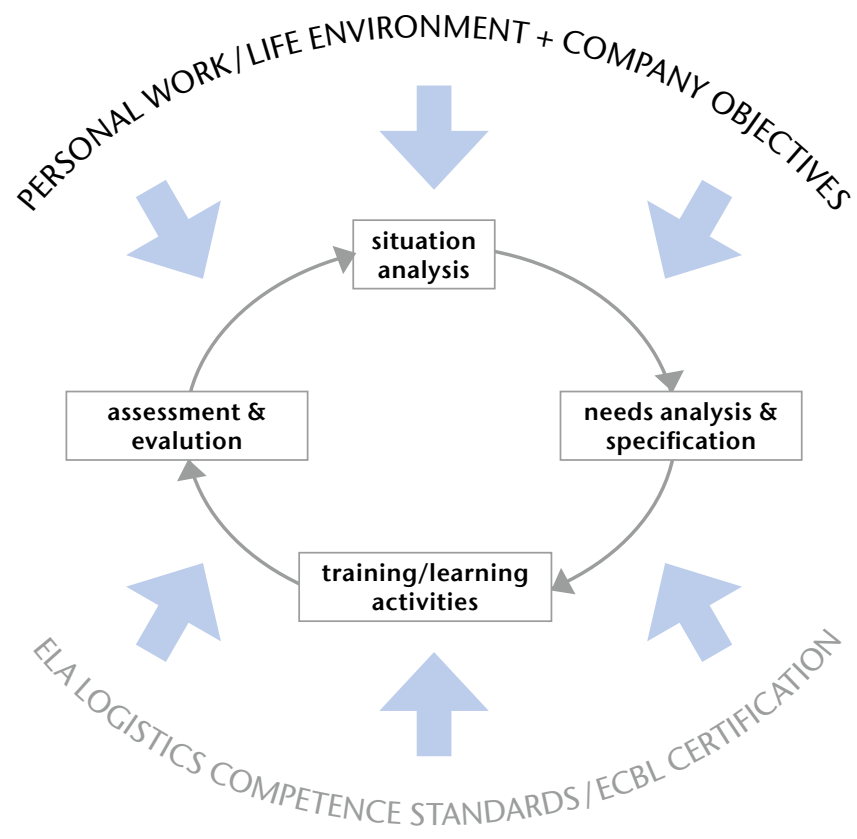

Fig. 1) Framework for systematic competence development in logistics (adapted from Neumann et al. 2005).

- Identification of training/learning activities enabling to reach those targets by purposeful and successful competence development.

- Assessment and evaluation of competence development activities in terms of both their success and their quality.

These core elements are to be understood as ongoing process which is cyclically repeated at increasing levels of competence. Starting point and target function of each new loop is formed by the respective work/life environment in which a person self-recognises particular fields of competence showing a gap between current and target levels.

Precondition for implementing the framework is a set of appropriate methods and tools for competence assessment. Here, commonly agreed professional standards like e.g. the Standards of Logistics Competence formulated by the European Logistics Association (ELA) provide an overall competence framework against which the European Certification Board for Logistics (ECBL), for example, examines and certifies logistics professionals at European level and beyond (ECBL 2004).
In addition to such kind of support for professional competence scanning and profiling another precondition for implementing the framework consists in the availability of appropriate training and learning activities to be offered to those who want to close a competence gap or simply want to be prepared for future. Training and learning might either belong to formal education and training programmes or be part of informal training and selflearning. Especially, the latter ways of learning and training outside a fixed, pre-defined and exactly scheduled framework are of growing importance since lifelong learning has become one of the key requirements in society and economy. Here, professionals and companies face particular challenges in both accepting the need for lifelong learning (or even better showing the wish for it) and providing or using opportunities for really "living" lifelong learning. The question is to what extent logistics professionals and companies already implemented this into their processes and activities.

Taking a closer look at activities related to any kind of training they often need to be considered quite time-consuming due to the large number and volume of available training material (Blümel et al. 2004). In contrast to this, time resources for attending classroom training or using e-learning during or after working hours are often limited. In the end, many employees lack further training and therefore do not improve their abilities to perform well at the changing labour market. On the other hand, limited real-time access to necessary information resources in the work place does not only hinder learning and competence development with the employees, but also can disturb working processes if certain terminology is not clear or background information on a subject are missing.

Some insights into the way company managers see and value this topic can be derived from an empirical impact study on the use of knowledge management in logistics companies from Portugal, Germany, Poland, Latvia and the Ukraine (Tomé et al. 2007). Amongst others, the companies' human resource managers were asked to qualitatively assess investments into different kinds of training (formal training, informal training, self-training) and to specify how important it is in their opinion to provide employees with access to those activities. One of the main findings was related to selftraining (ST - see Figure 2):

- Self-training was the knowledge management activity with the highest average investment per company. This is interesting as looking into today's companies you typically find a large variety of formal training offers, but just very few selftraining opportunities. Probably, this result therefore is an expression of current initiatives by company management for widening the scene into this direction.

- Self-training belonged to those knowledge management activities showing the highest average level of priority with the companies. The fact that HR managers give this high priority to accessing self-training illustrates that companies expect their employees to take responsibility for their own further development 
- Self-training was found in the middle of the field when it comes to potential needs for changes in the level of investment. The overall low value shows that company policy regarding investments into selftraining quite well reflects the priority for accessing self-training. As a result almost no changes or just a little more investment is needed.

Seeing all knowledge management activities that were subject to investigation it seems that companies require and favour their employees' own initiatives for gaining, deepening, updating knowledge (which eventually would cost the company the least). But at the same time companies need to be aware of their responsibility to provide their human resources with some freedom and time for those activities. To achieve this, new technological, methodological and organizational solutions are needed, which seamlessly need to be integrated into company-settings and professional life, i.e. approaches like workplace learning and training-on-the-job have to be implemented.
Following findings from the study discussed above, workplace learning should to be designed in a kind of self-training approach, that (i) meets specific challenges, requirements, and preferences of the employee and (ii) is easily accessible and seamlessly embedded into the working environment. E-learning might work well here if being designed in small portions which do not require a significant time - 'stolen' from the working time - to gain additional knowledge or improve specific competences. According to Jonassen (2001) those e-learning activities should be used for creating learning-by-doing and perceptual environments for problem-based learning, where you are immersed in making rapid-fire decisions, rushing to gain new information, utilizing the expertise of colleagues, and relying on your ability to create and store useful knowledge that will allow you to innovate and get your products to market way before your competitor.

\section{III.COMPETENCE REQUIREMENTS IN LOGISTICS PRACTICE}

Discussions in the previous section resulted in two major findings. First of all, training should as much as possible be integrated in working processes, i.e. any training offer must be available wherever and whenever a logistics professional feels the need for and faces an opportunity to deal with it. This is to be achieved by using e-learning as delivery method. As second finding it became clear that those training offers can only be successful when matching with training needs. Training needs reflect a gap between current and required or intended professional competencies. This can only be ensured by knowing about competence requirements in logistics practice and understanding a person's individual level of professional competence achieved so far.

Exactly these needs were the reasons for running a questionnaire-based survey with logistics managers at different management levels and from different types of (logistics) companies within the lot4eng.com project. The survey aimed at ensuring that e-learning materials to be developed within the project match current requirements at the logistics labour market. Its outcomes formed the basis for developing web-based, interactive

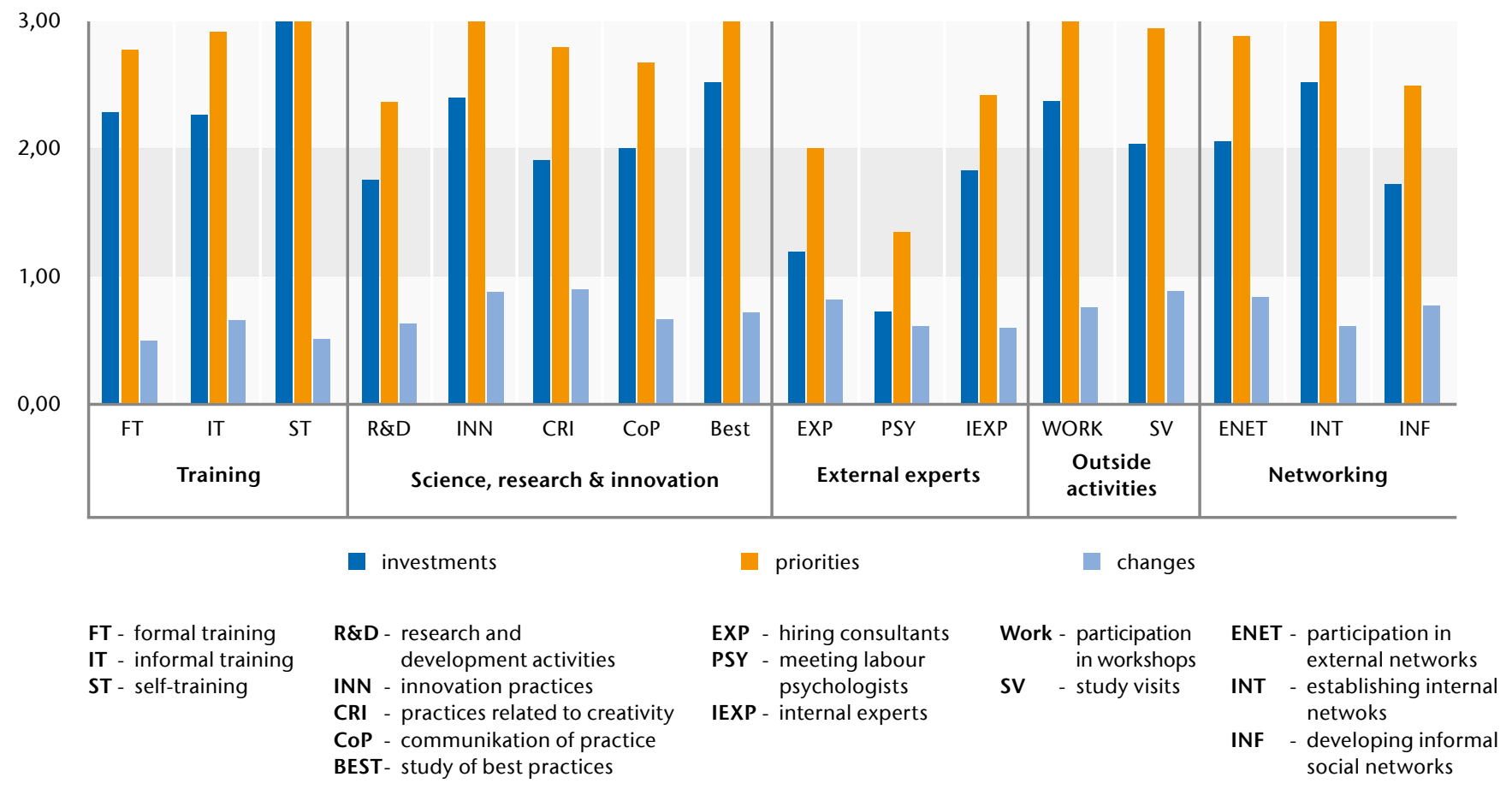


training materials addressing those needs and enabling logistics practitioners (but also newcomers to the field) to develop and improve professional competencies according to their individual requirements.

In the survey participants were asked to indicate the level of thinking (according to Bloom's Taxonomy of educational objectives (Bloom 1956, see Table 1) they would expect to find with a logistician at a certain management level (i.e. strategic, tactical or operational) for 20 managerial and 20 engineering competence areas. Here, each level always includes competence requirements of all lower levels up to the target one. By combining each competence area with the Bloom level that seems to represent best what a practitioner might be expected to be able to do in this field a specific competence requirement was created.

Comparing the frequency distribution of all responses to all questions related to managerial competences (see Figure 3a) and engineering competences (see Figure $3 \mathbf{b}$ ) it became visible that the required level competence varies between management levels (see Table 2).

From this it can be concluded that e-learning materials aiming to develop, to improve or "just" to maintain specific or generic management or engineering competences with a logistician need to be designed in a way helping to accomplish different competence levels as specified above. For this a series of modules is required which should be sub-structured into units each of them addressing a well specified competence aspect at a level contributing to the overall competence development as intended. There is no need for all modules or units to always address the target competence levels, but in total a combination of units (or even modules) has to enable the logistician to reach the goal. This can only be achieved by providing competence-based and learning-goal oriented access to different parts of the material, and enabling interactive knowledge application through quizzes at different levels of difficulty and analyzing or running case studies at different levels of complexity.

\begin{tabular}{|c|c|}
\hline Level & Competences \\
\hline $\begin{array}{l}\text { Evaluation } \\
\quad(\mathrm{EV})\end{array}$ & $\begin{array}{l}\text { You can pass judgment on something. } \\
\text { (e.g. assess, conclude, decide, verify) }\end{array}$ \\
\hline $\begin{array}{l}\text { Synthesis } \\
\text { (SY) }\end{array}$ & $\begin{array}{l}\text { You can create something new as a result of analysis. } \\
\text { (e.g. compose, create, design, generate, plan) }\end{array}$ \\
\hline $\begin{array}{l}\text { Analysis } \\
\text { (AN) }\end{array}$ & $\begin{array}{l}\text { You can break something down. } \\
\text { (e.g. compare, detect, order, simplify) }\end{array}$ \\
\hline $\begin{array}{l}\text { Application } \\
\text { (AP) }\end{array}$ & $\begin{array}{l}\text { You can take something from one context and use it in another. } \\
\text { (e.g. choose, collect, complete, develop, use) }\end{array}$ \\
\hline $\begin{array}{l}\text { Comprehension } \\
\text { (CO) }\end{array}$ & $\begin{array}{l}\text { You understand what you know. } \\
\text { (e.g. associate, classify, differentiate, explain, identify, summarize) }\end{array}$ \\
\hline $\begin{array}{l}\text { Knowledge } \\
(\mathrm{KN})\end{array}$ & $\begin{array}{l}\text { You know something. } \\
\text { (e.g. define, describe, list, match, name, relate) }\end{array}$ \\
\hline
\end{tabular}

Tab. 1) Bloom's Taxonomy (adapted from University of Limerick, 2007).

a) Overall number of responses per competence level (managerial competences)

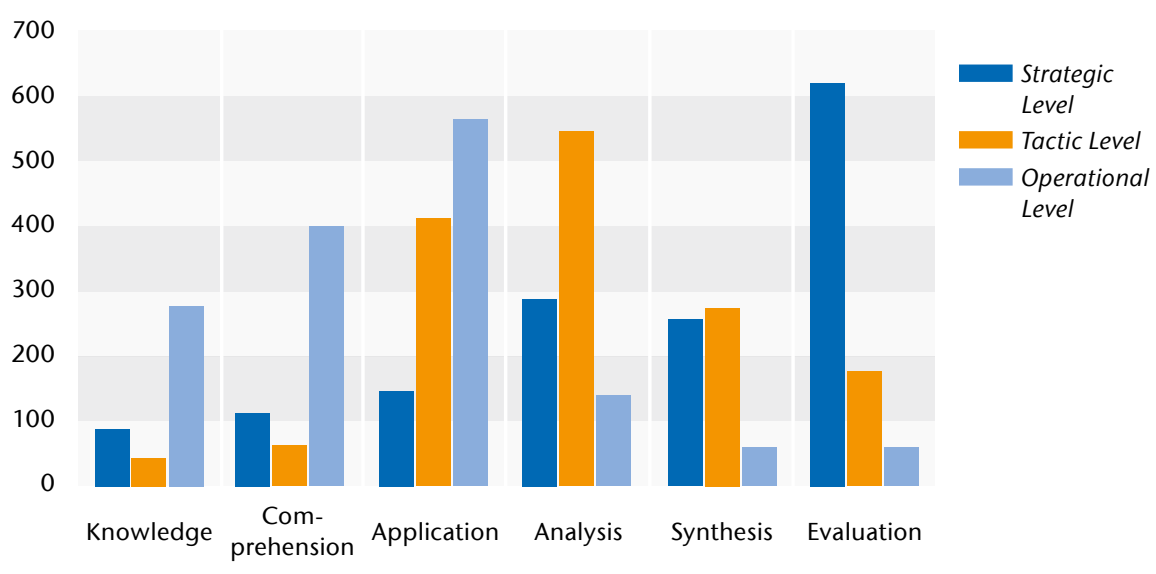

b) Overall number of responses per competence level (engineering competences)

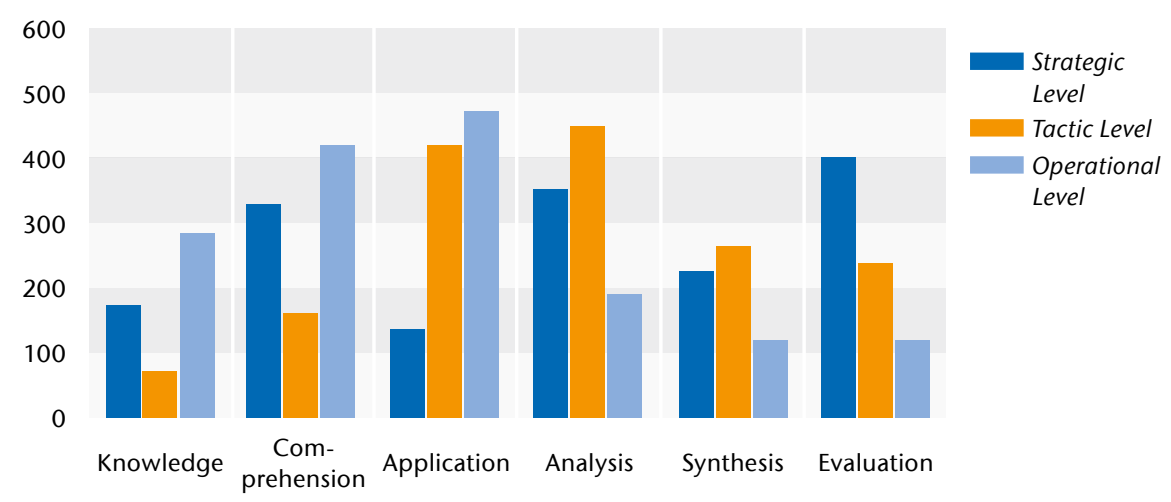

Fig. 3) Competence requirements in logistics practice. 
Comprehension / application: Operational

Operational management level

logistics managers are expected to discuss and interpret logistics basic concepts, strategies, performance indicators etc. in order to apply this knowledge for effectively and efficiently operating in logistics.

Tactical management level

Analysis: Tactical logistics managers are expected to look for patterns, trends and ideas in logistics and apply them to manage, control, and improve logistics processes and systems.

Strategic Analysis / synthesis: Strategic managers are management additionally expected to also propose alternative level logistics solutions.
Application: Operational logistics managers are expected to apply understanding on the technological background of logistics operation for effectively and efficiently running logistics.

Analysis: Tactical or strategic logistics managers are expected to go into detail with technological requirements and solutions in logistics, be able to select proper technology for existing systems and new system's design, and apply suitable methodology like calculation, model building or simulation.

Analysis: Tactical or strategic logistics managers are expected to go into detail with technological requirements and solutions in logistics, be able to select proper technology for existing systems and new system's design, and apply suitable methodology like calculation, model building or simulation.

Tab. 2) Conclusions on practical competence requirements with logisticians.

\section{LOT4ENG.COM - LOGISTICS OPEN TRAINING FOR ENGINEERING COMPETENCE}

The lot4eng.com platform was designed exactly to provide this kind of support. It addresses three target groups: logistics managers, logistics engineers and logistics teachers. Whereas the first two groups of users aim to improve their logistics competences according to requirements as elaborated in Section 3, logistics teachers are particularly supported in developing (further) their knowledge, skills and abilities in applying information and communication technologies, web 2.0 and modern pedagogy to logistics education and training. For this, the platform currently provides 15 e-learning modules (see Table 3) comprised of about 125 learning units. All e-learning material is freely accessible (after registration to the platform), contains multimedia elements, is interactionbased, encourages knowledge application and is available in English as well as in the local languages of those countries that were addressed by the lot4eng.com project (Poland, Italy and Germany).

In order to help the user in selecting those e-learning materials that are most appropriate for his/her individual competence development, the platform needs a kind of continuously updated, personalized user profile.
This results from information provided by the user when

registering to the platform,

- selecting his/her overall competence area of interest, i.e. managerial competences (managers), engineering competences (logistician) or training competences (teachers),

- going through an area-specific competence test, and

- working with e-learning material that was either self-selected or previously recommended by the platform.

User information are analysed by a diagnosis tool to identify competence gaps. Here, user's competences as demonstrated in the test are matched against the target competence level as required from the competence survey. The test is composed by randomly chosen questions from a pool which are all related to a particular area and level of competence and linked to one or more learning units helping in achieving or improving the respective competences. Depending on the outcomes of this competence diagnosis the user receives feedback on the current competence level and to what extent it meets professional requirements. If a particular gap has been identified, a list of e-learning units is proposed with the help of which missing competences might be developed. In case of a more complex development process needed learning units are additionally linked into a personalized learning path, helping the user in extending and improving competences in a systematic way.

\section{E-LEARNING DESIGN TO SUPPORT INDIVIDUAL COMPETENCE DEVEL- OPMENT IN LOGISTICS}

Precondition for e-learning material and learning units being suitable to enable and support individual competence development in a systematic way is their proper design. First of all, e-learning material needs to be up-to-date in terms of contents, attractive in terms of its presentation, interactive in terms of involvement of the user. In addition to those characteristics, implementation of alternative pedagogical strategies is helpful in order to allow learning processes that match with personal preferences. Concerning the latter Atolagbe, Hlupic and Taylor (2001), for example, identified the following concepts as particularly suitable ones for competence development:

- Learning with scenarios (i.e. using a real-world scenario as the vehicle for instruction);

- Learning by doing (i.e. coaching in step-by-step operations required to perform a particular task); 
Human Resource Management

Analysis and re-engineering of information processes

Managers

THW

\begin{tabular}{|c|c|c|}
\hline Analysis and re-engineering of information processes & Managers & WSL \\
\hline Informative systems of commercial and distribution companies & Managers & WSL \\
\hline Project management & Managers & THW \\
\hline Introduction to international business & Managers & WSL \\
\hline Information technology & Managers & THW \\
\hline Application of logistics software & Managers & THW \\
\hline Informative systems of production companies & Managers & WSL \\
\hline Negotiation and cross-cultural communication & Managers & WSL \\
\hline Technological foundations of logistics and SCM & Logisticians & WSL \\
\hline Introduction to materials handling technology & Logisticians & THW \\
\hline Analysis and design of logistics systems & Logisticians & THW \\
\hline Specification of requirements, tendering and bidding for logistics systems & Logisticians & WSL \\
\hline Logistics Information Systems & Logisticians & THW + WSL \\
\hline E-learning in Web 2.0 & Teachers & CSPMI \\
\hline
\end{tabular}

Tab. 3) E-Learning modules within the lot4eng.com platform.

- Practicing with contents feedback (i.e. providing remediation of a problem whenever an error or misconception has been detected); and

- Free exploration (i.e. enabling navigation around a case scenario without intervention by the learning environment).

This way informal self-learning is supported rather than formalized educational processes. For the purpose of the lot4eng.com project this exactly met intention: support workplace learning with logistics practitioners who want to or need to apply knowledge and methods for logistics problem solving in their daily work. This is achieved best by offering instruction-like and problem-based modules (Neumann 2008) strengthening practical knowledge transfer, whereas description-oriented modules focusing on transferring theoretical knowledge are less suitable here.

Consequently, e-learning modules contributed by TH Wildau (see Tables 4 and 5) combine presentation of knowledge and facts to grasp concepts with quiz- zes and tasks for testing and deepening their understanding; problem-based scenarios and practical questions demand for critical thinking and applying concepts.

In order to help the user in orientating him/herself all modules are designed along the same lines:

- Each module is structured into a different number of units each of them focusing on specific aspects and competences within the area of the module. This means each unit can be used separately and independently of other units of the same module. On the other hand units from different modules can be combined into personal learning paths matching individual needs for competence development.

- Each unit starts with an overview (see Figure 4) providing information on a unit's learning objectives and eventually relevant preconditions for successfully working with it. Furthermore, main topics covered by the unit are presented in a mind map; quite often this is being done in the form of question to which the answers the user might find in the unit.

- Each unit ends with a summary of relevant terms to remember and a quiz for self-testing the knowledge and understanding acquired. The quiz is not the same as the platform's competence check, but aims to help the user in getting a picture on whether or not his/her learning was successful or what he/she eventually should repeat, as significant terms or concepts could not be reproduced.

- In each unit the content is organized in a straight line following a simple learning path. Nevertheless, there are some places where additional information was felt to be useful in order to provide some background knowledge or remind of fundamentals for the main topic. Further information are either embedded in a pop-up window that easily can be closed again without leaving the unit's main track or they are presented on separate pages from which the user can go back to where he/she came from. 
Information

Technology

This module helps in achieving a basic understanding on information technology and its role in logistics.
This module helps in achieving a basic

Human Resource understanding on Human Resource Management (HRM)

Management and its application in the logistics sector.

Staff Recruitment/Selection

Staff Deployment

Staff Development

Laying-off Staff Members

Modern Methods in HRM

This module helps in achieving a basic understanding on the role and kind

Application of Logistics Software

Software in Logistics

Introduction to Simulation of software used in logistics. Furthermore, simulation and visualization are presented as specific areas of software application.
Coding

Databases

Informatics Basics

Information Networks

Logistics Informatics

Information Security Pseudocodes

Telecommunication

Sort Algorithms

Introduction to PM

Classification of Projects

Project Organization

Project Planning

Project Teams

Project Boards

Project Communication

Communication in Teams

Project Completion

Introduction to HRM

Staff Management Staff Planning

$\mathrm{CO}$

$\mathrm{KN}$

$\mathrm{KN}$

$\mathrm{CO}$

SY

$\mathrm{KN}$

AP

KN

AN

$\mathrm{CO}$

$\mathrm{CO}$

AN

AP

$\mathrm{CO}$

AP

AN

AP

AP

$\mathrm{CO}$

$\mathrm{CO}$

AP

CO

$\mathrm{AP}$

AN

AP

AP

How to Run a Simulation Project

Simulation Using DOSIMIS-3

Visualization Using taraVRbuilder
EV

$\mathrm{CO}$

AP

EV

EV

Table 4) Description of managerial e-learning modules contributed by TH Wildau.

Module

Introduction to

Materials Handling

Technology

(MHT)

Analysis and Design of Logistics Systems

Logistics Information Systems

(LIS)

\section{Description}

This module helps in achieving a basic understanding on materials handling technology and its role in logistics. The main focus is put on introducing the wide variety of technology used to enable material flows in order to allow their purposeful selection and implementation.

This module helps in achieving a basic understanding on how to analyse and design logistics systems (and processes). Particular focus is put on both general procedure and particular methods suitable for intralogistics and/or network analysis and design.

This module helps in achieving a basic understanding on the role of information in logistics management. For this key application areas are presented and relevant systems are introduced.
Materials Handling

Packaging and Unit Loads

Materials Handling Equipment Storage Systems

AP

AP

Storage/Retrieval Equipment

Automatic Identification

Material Flow Analysis

Procedure in Material Flow Planning AP

Planning of Warehouses

Reliability for Intralogistics

Introduction to LIS

Tracking and Tracing

Standards in Information Flows

Identification Methods and Technologies

Logistics Management Systems
$\mathrm{CO}$

AN 
In order to allow streamlined implementation on one hand and ensure easy re-usability of material on the other, e-learning units were built as a sequence of HTML pages rather than a monolithic package (in the form of Flash films) resulting from modern e-learning authoring tools. HTML pages are interlinked, but apart from this
Whether or not this concept and related implementation ideas work is to be shown by testing and evaluating the learning material. Although e-learning material is not meant to be used in university classes, first use cases were related to regular courses. One of those test beds was formed by the introductory course in informatics that is run achieved. Here, almost $50 \%$ of all students from group 2 reached good or very good results, whereas in group 1 this was the case for a little more than $30 \%$ of the students only. Although this evaluation was more observationbased than scientifically grounded, it at least allows drawing some general conclusions. Students were curios and

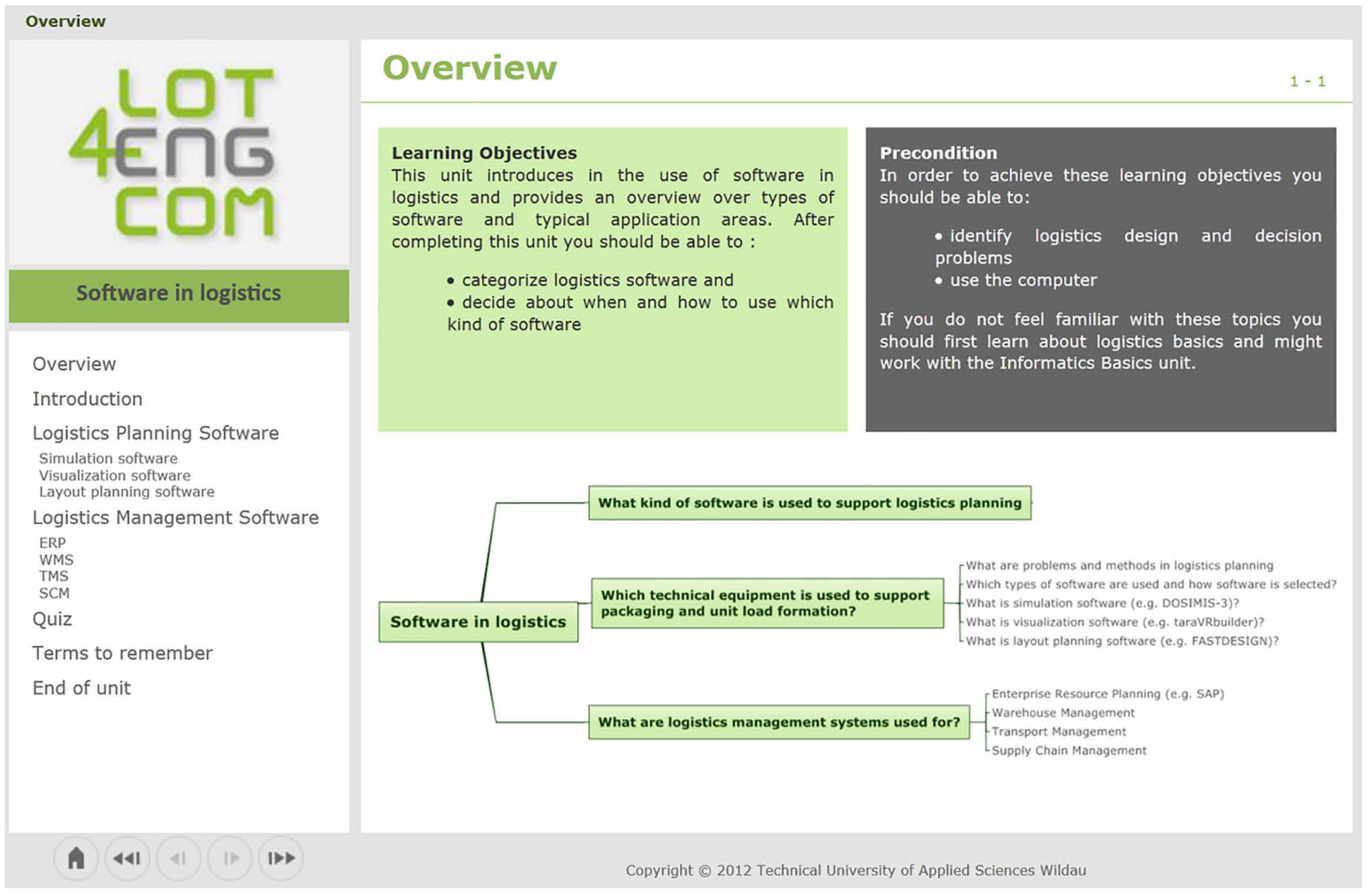

Fig. 4) E-learning unit design.

they work fully independent of each other. Therefore, any pages fitting into another unit as well can simply be embedded in its structure without reimplementation. For the purpose of increasing user engagement and raising attractiveness multimedia material, like e.g. films or animations, was used, but also interactive graphics or little quizzes (usually in the form of Flash films) have been integrated when they appeared useful. Although Flash films seemed to be a good solution, they nevertheless increase loading time of a unit or page. Because of this, sequences were tried to be kept short. with different student groups but by the same teacher. Both student groups were taught in the same way and had access to the same kind of material. In addition to this "standard" package, students from group 2 also had the chance for accessing extra material on a voluntary basis, i.e. relevant e-learning units including exercises. As results show (see Figure 5) those extras were quite frequently used - typically as add-ons to other (more traditional) sources. Comparing examination results for those groups there is a slightly better average with group 2 instead of group 1. This difference becomes more visible when having a closer look at the frequency distribution of marks interested in using e-learning materials in addition to their standard course materials and examination results eventually improve due to working through additional exercises. Obviously, e-learning material offered on a voluntary basis was attractive enough to keep students motivated in using it and rich in content enough to increase some competences related to the basic concepts of informatics.

Of course, this first trial could only be the starting point for more systematic testing and evaluation by the "real" beneficiaries of the lot4eng.com project. Evaluation of e-learning materials was part of a dedicated testing phase 
of the entire lot4eng.com platform including competence gap analysis and learning path recommendation. Learning success was tested by a postlearning competence check and user feedback on the quality and design of e-learning material was collected by use of respective questionnaires. Results were analysed and partially led to revision and further improvement of the material.

\section{SUMMARY AND CONCLUSIONS}

The need for education and training in logistics is widely accepted by individuals, companies and the academic world. Special challenges for trainingon-the-job consist in the needs (i) to meet specific challenges, requirements, and preferences of the employee and (ii) to be easily accessible and seamlessly embedded into the working environment. The lot4eng.com project as presented in this paper provides an e-learning-based approach that aims to support logistics managers and engineers in updating and extending their professional competence. Due to their daily workload time resources for attending classroom training are often limited; therefore learning while working, i.e. workplace learning, is a more promising approach. Adequately designed e-learning materials and a portal environment that allows to individually check professional competence gaps and to recommend a learning path suitable to close those gaps form a promising basis for personalized lifelong learning.

Although testing and evaluation of both portal functionality and e-learning materials is still in progress it must be clear that the portal will only be a successful tool if continuously being improved and updated. A critical amount of learning material has already been implemented, but topics covered so far are far away from representing all aspects and competence areas. Therefore, post-project revision processes need to be set up.

Furthermore, the project was facing some drawbacks concerning the distributed authoring process. Instead of developing, implementing and translating a particular e-learning material by each partner individually without

a) Which material or which source did you use?

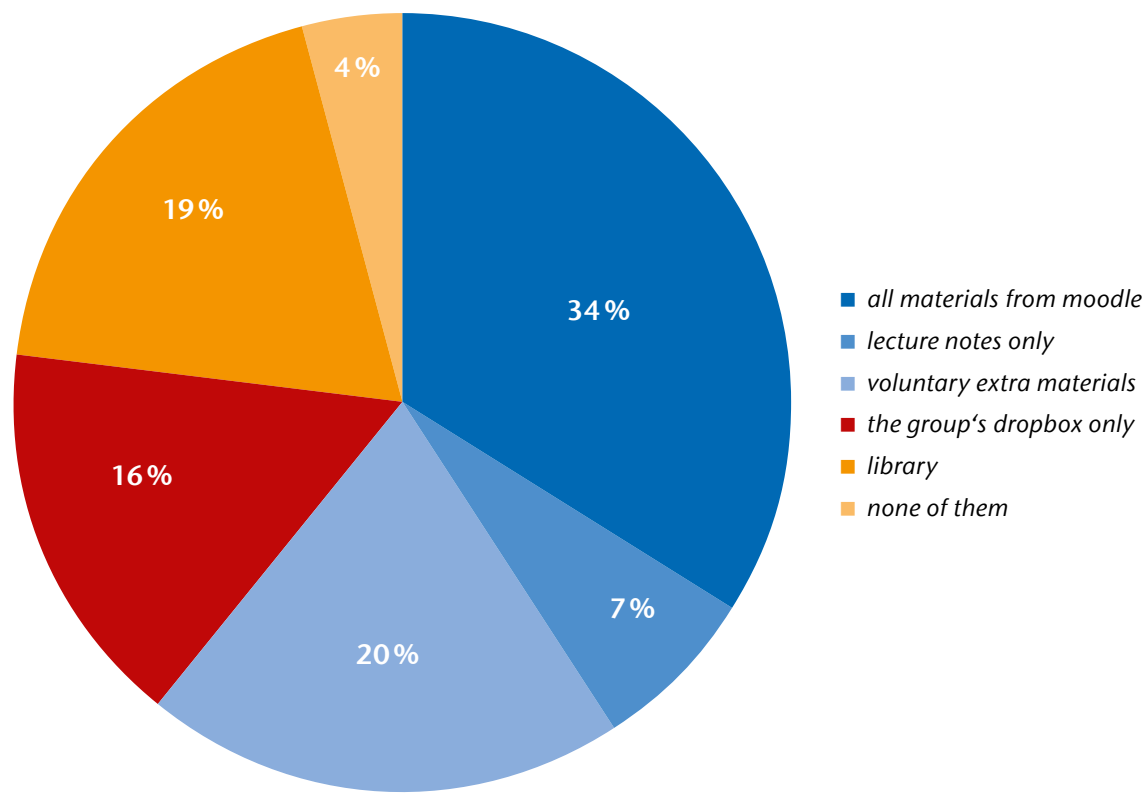

b) Examination results

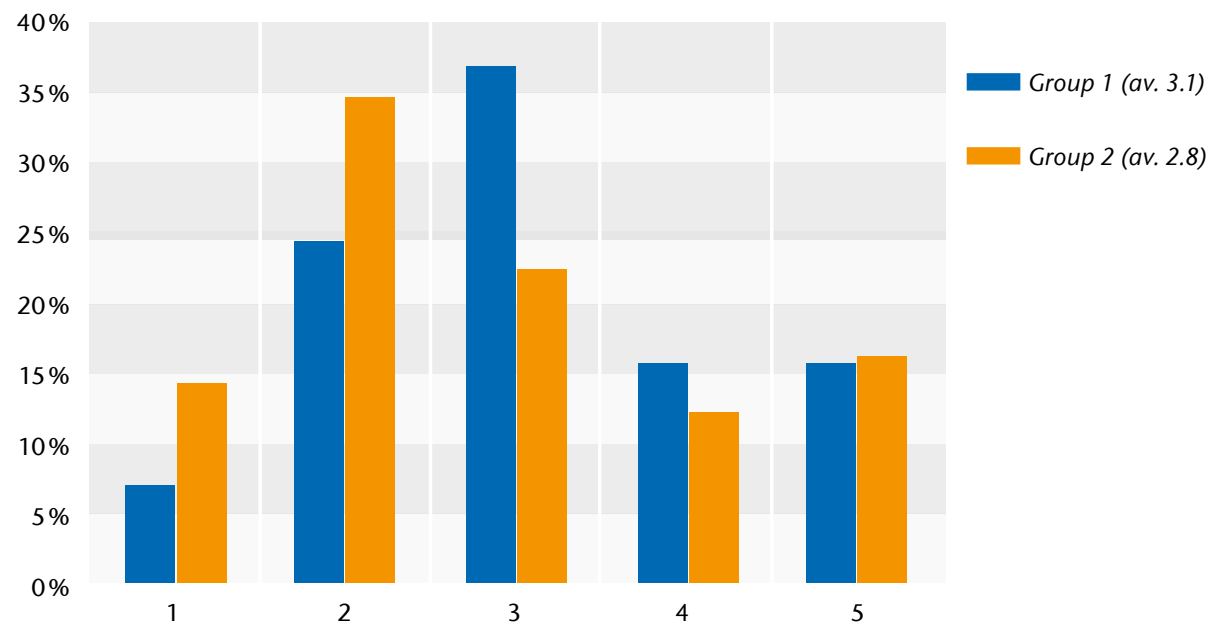

Fig. 5) Results from first evaluation of the e-learning material.

cross-checking which content areas are covered by other partners, the better and generally more efficient approach would have been to internally exchange developed materials in the English language, gain feedback by partners and link it into the overall content network of the portal prior to spending translation and final implementation efforts.

\section{ACKNOWLEDGMENTS}

This paper is based upon the outcome of the lot4eng.com project "Logistics Open Training for Engineering Com- petence". This project was funded with support from the European Commission under the Lifelong Learning Programme. This communication reflects the views only of the authors, and the Commission cannot be held responsible for any use which may be made of the information contained therein. 


\section{LITERATURE}

Atolagbe, T.; Hlupic, V.; Taylor, S.J.E. 2001: Genisa: A Web-Based Interactive Learning Environment for Teaching Simulation Modelling. In: Proceedings of the 2001 Winter Simulation Conference. eds. B.A. Peters; J.S. Smith; D.J. Medeiros; and M.W. Rohrer. pp. 16051612

Bluemel, E.; Ginters, E.; Guasch, A.; Neumann, G.; Novitski, L; Paulauskas, V. 2004: Competence Framework for Mobile On-Site Accelerated Training in Logistics Information Systems - LOGIS MOBILE. In: Proceedings of HMS 2004 - International Workshop on Harbour, Maritime and Multimodal Logistics Modelling and Simulation, pp. 169-172.

Bloom, B. S. 1956: Taxonomy of educational objectives: the classification of educational goals: handbook I, cognitive domain, David McKay Co Inc. New York.

European Commission 2007: KEY COMPETENCES FOR LIFELONG LEARNING. European Reference Framework. Luxembourg: Office for Official Publications of the European Communities.

European Certification Board for Logistics (ECBL) 2004 ELA Standards of Logistics Competence; European Logistics Association (ELA): Brussels.

Jonassen, D. H. 1991: Evaluating Constructivistic Learning. Educational Technology, 31(9), pp. 28-33.

Jonassen, D. H. 2001: E-Learning to Solve Problems. Keynote of ED-MEDIA World Conference on Educationa Multimedia and Hypermedia 2001 (Tampere, Finland, June 25-30, 2001)

Neumann, G. 2008: Simulation Education in Logistics: Case Studies in a Virtual Learning Environment. In: Proceedings of the 22nd European Conference on Modeling and Simulation. eds. L.S. Louca; Y. Crystanthou; Z. Oplatková; and K. Al-Begain. pp. 441-446.

Neumann, G.; Decker, J. (2005): Kompetenz in der Logistik. In: Wolf-Kluthausen, H. (ed.): Jahrbuch Logistik 2005. Korschenbroich: free beratung $\mathrm{GmbH}$, pp. 286290. (Competence in logistics; in German).

Ryan, M.; Woodward, L.1998: Impact of Computer Mediated Communication (CMC) on Distance Tutoring In: Proc. ED-MEDIA 1998, AACE Publishing: Freiburg (Germany) (1998), pp. 1203-1207.

Tomé, E., Neumann, G. 2007: Knowledge Managemen and Logistics: A European Perspective, Martin, B. and Remenyi, D. (eds.), The 8th European Conference on Knowledge Management, vol. 2, pp. 1009-1016.

University of Limerick 2007: Writing Learning Outcomes - A Guide for Academics. University of Limerick.

\section{AUTHORS}

Prof. Dr.-Ing. Gaby Neumann Technische Hochschule Wildau,

Fachbereich Ingenieur- und Naturwissenschaften Hochschulring 1, 15745 Wildau

Tel.: +49-3375/508-147

E-Mail: gaby.neumann@th-wildau.de

Dipl.-Kaufmann Michael Müller

Technische Hochschule Wildau,

Fachbereich Ingenieur- und Naturwissenschaften Hochschulring 1, 15745 Wildau

Tel.: +49-3375/508-925

E-Mail:michael.mueller@th-wildau.de

\section{Rudi Köhler B.Eng.}

Technische Hochschule Wildau,

Fachbereich Ingenieur- und Naturwissenschaften

Hochschulring 1, 15745 Wildau

Tel.: +49-3375/508-658 